\title{
Aminoacid constitution of two gastrins isolated from Zollinger-Ellison tumour tissue
}

\author{
R. A. GREGORY, HILDA J. TRACY, K. L. AGARWAL, \\ AND M. I. GROSSMAN \\ From the Physiological Laboratory, and the Robert Robinson Laboratory of \\ Organic Chemistry, University of Liverpool, and the Veterans Administration \\ Center, Los Angeles, USA
}

SUMmaRY Two peptides which are potent stimulants of gastric acid secretion are isolated from Zollinger-Ellison tumour tissue. They have aminoacid constitutions identical with those of human gastrin types I and II as isolated from human antral mucosa, and they are present in similar proportions. Their electrophoretic and chromatographic behaviour corresponds to that of human gastrins. Evidence is presented in respect of the one isolated in greater amount that its aminoacid sequence is probably identical with that of human gastrin type I.

It is now well known that in many cases of the Zollinger-Ellison syndrome as characterized by gastric hypersecretion, peptic ulceration, and a nonbeta-cell pancreatic tumour, a gastric secretagogue which is neither histamine nor insulin has been extracted from the tissue (primary or metastatic); it shows the same spectrum of physiological actions as do the pairs of peptides which have been isolated from the antral mucosa of several species (including man), and which are generally agreed to represent the hormone gastrin (Gregory and Tracy, 1964; Gregory, 1968). This strongly suggests that the secretagogue present in such tumours is gastrin but decisive evidence on this point can only be provided by isolation of the secretagogue in amounts sufficient for a definitive study of its chemical nature.

Gregory, Grossman, Tracy, and Bentley (1967) isolated from $19.5 \mathrm{~g}$ of Zollinger-Ellison tumour tissue $104 \mu \mathrm{g}$ of a product which stimulated gastric acid secretion in conscious dogs and showed a quantitative aminoacid composition in very good agreement with that of human antral gastrin peptide. The amount of material available was so small that it was impossible to ascertain whether it comprised one or other, or both, of the two peptides present in human antral mucosa; and no evidence could be offered in respect of the aminoacid sequence compared with that of the antral peptide.

In a further study on this problem two biologically active peptides have been isolated from a larger amount of such tumour tissue; they appear to be identical with the human antral gastrins I and II, and are present in similar proportions. An account of the work was presented in July 1968 at a symposium on non-insulin-producing islet cell tumours of the pancreas held at Erlangen, West Germany (to be published).

\section{EXPERIMENTS}

PREPARATION OF A CRUde TUMOUR EXTRACT Pancreatic tumours or metastatic nodules obtained from cases diagnosed clinically as examples of the Zollinger-Ellison syndrome were thinly sliced and the fragments thrown into vigorously boiling water. After five minutes the mixture was cooled, the liquor decanted, and the fragments ground with silver sand. The ground material was washed from the sand back into the liquor with water and the suspension made approximately $p \mathrm{H} 9$ by dropwise addition of strong ammonia solution (sp gr 0.880 ). After stirring for one hour the suspension was clarified by filtration through cottonwool; the final volume of extract was equivalent to about 100 times the weight of fresh tissue.

Two grams of diethylaminoethylcellulose powder (Whatman DE 11) were precycled with acid and alkali and freed from 'fines' as recommended by the manufacturers and then added to the tumour extract; the $\mathrm{pH}$ was brought to 8.5 by dropwise addition of glacial acetic acid and the suspension was stirred for one hour. The DE was collected on a small Buchner funnel using suction and a coarse paper (Green 904); it was then removed and suspended in $20 \mathrm{ml}$ of $0.2 \mathrm{~N} \mathrm{NaOH}$ for 15 min with occasional stirring. The extract was collected by suction filtration and neutralized to $p \mathrm{H} 7$ by drop- 


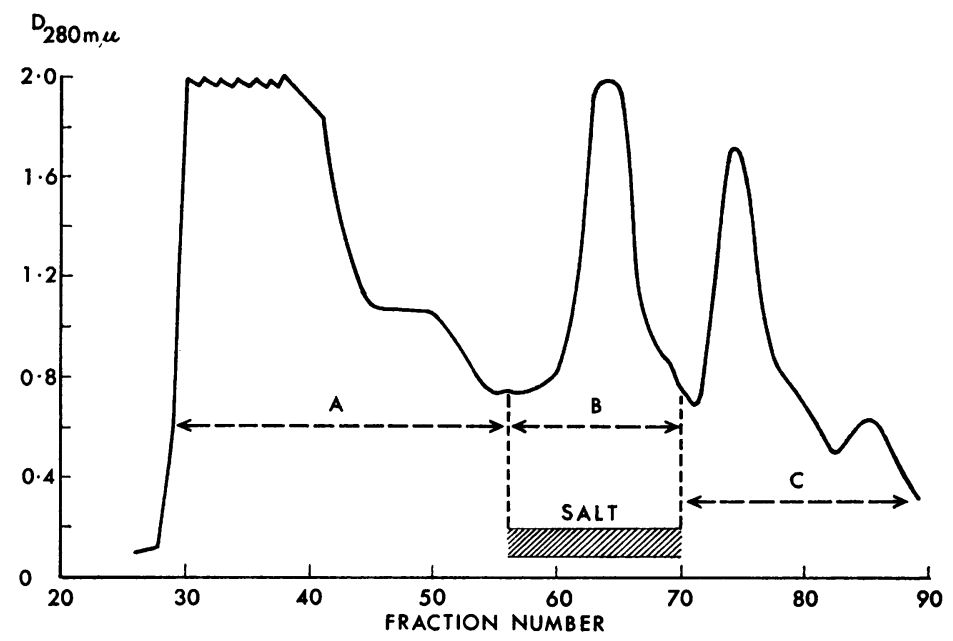

FIG. 1. Fractionation on Sephadex $G 25$ of a partially purified extract of Zollinger-Ellison tumour tissue.

wise addition of $10 \mathrm{~N} \mathrm{HCl}$. An aliquot was taken for testing by injection into conscious dogs or cats. If active, the remainder of the extract was lyophilized and stored at a temperature of $-20^{\circ} \mathrm{C}$ or lower for later use.

Assays Conscious dogs provided with completely denervated fundic pouches (Gregory, 1958) and fasted 18 hours were infused subcutaneously with carbachol at the rate of 2.5 to $5.0 \mu \mathrm{g}$ every 15 minutes the dose for a particular animal was determined by trial as that which did not result in a secretion of acid by the pouch when continued for a period of six hours. This 'background' of cholinergic stimulation markedly increased the sensitivity of the pouch so that responses to the subcutaneous injection of as little as $1 \mu \mathrm{g}$ gastrin or Peptavlon (ICI) were consistently obtained. Solutions to be tested for gastrin activity were injected subcutaneously at a site different from that used for the carbachol infusion.

Some DE eluates were assayed for gastrin activity by slow intravenous injection in conscious cats provided with gastric fistulae as described by Uvnäs and Emås (1961).

ISOLATION OF PEPTIDES FROM THE TUMOUR EXTRACT The isolation procedure described below was carried out using lyophilized DE extract equivalent to a total of about $50 \mathrm{~g}$ fresh tumour tissue. The material was processed in three separate portions to minimize loss in the event of an accident. Further small amounts of material were also used during the development of the method; for various reasons the products of these trials were not included in the material used for the final analyses.

An amount of powder equivalent to 10 to $20 \mathrm{~g}$ of fresh tumour was dissolved in $25 \mathrm{ml}$ of water; to the solution was added $0.5 \mathrm{ml}$ of strong ammonia solution ( $\mathrm{sp} \mathrm{gr}$ 0.880 ). In the solution $12.5 \mathrm{~g}$ of powdered anhydrous dipotassium hydrogen phosphate $\left(\mathrm{K}_{2} \mathrm{HPO}_{4}\right)$ was dissolved, with constant stirring, in a water bath at room temperature. Then $17 \mathrm{ml}$ of peroxide-free isopropanol was dripped in with vigorous stirring. The mixture was briefly centrifuged and the upper layer removed. To the lower phase was added $15 \mathrm{ml}$ of the upper phase of a mixture of $50 \mathrm{ml}$ water, $1 \mathrm{ml}$ strong ammonia solution, $25 \mathrm{~g} \mathrm{~K}_{2} \mathrm{HPO}_{4}$, and $37 \mathrm{ml}$ isopropanol. After vigorous shaking for one minute and then briefly centrifuging the upper phase was removed. This extraction was repeated once more and the combined isopropanol extracts were then shaken with 3 volumes of peroxide-free ethyl ether after the addition of $5 \mathrm{ml}$ water. After brief centrifuging the aqueous phase was collected. Five $\mathrm{ml}$ of water was added to the ethereal phase; the mixture was shaken and then briefly centrifuged. The aqueous layer was collected and the ethereal layer discarded. The combined aqueous fractions were extracted twice with 2 volumes of ether, briefly centrifuging each time and discarding the ethereal phase. The aqueous residue was freed from ether by a current of air in partial vacuum and then lyophilized.

The residue was dissolved in $1 \mathrm{ml} \mathrm{H}_{2} \mathrm{O}$ and applied to a column of Sephadex G 25 superfine bead form $1.5 \mathrm{~cm}$ $\times 50 \mathrm{~cm}$ packed in $0.04 \mathrm{M}$ ammonium bicarbonate solution. The effluent was collected in fractions of $1.3 \mathrm{ml}$ every 15 minutes and these read at $280 \mathrm{~m} \mu$. Non-volatile salt (phosphate from the isopropanol extraction) was located by conductivity determinations on each fraction. Gastrin activity was located by testing pooled one-drop aliquots from selected groups of fractions.

A typical result is shown in Fig. 1; regions $A$ and $B$ contained secretagogue activity, $C$ was inactive. The fractions corresponding to A and B were pooled separately, lyophilized, and dissolved in buffer for refractionation.

Fraction A was applied in a volume of $0.5 \mathrm{ml}$ to a column of Sephadex G 50 superfine bead form $1 \mathrm{~cm} \times$ $100 \mathrm{~cm}$ packed in $0.04 \mathrm{M}$ ammonium bicarbonate solution. The effluent was collected in fractions of $0.4 \mathrm{ml}$ every 15 minutes and these read at $280 \mathrm{~m} \mu$. A typical result is shown in Fig. 2; secretagogue activity was found in the shaded region, well in advance of the position of the 'salt zone' on this column. The appropriate fractions were pooled, lyophilized, and redried in vacuo over phosphoric oxide until free from ammonium bicarbonate. 


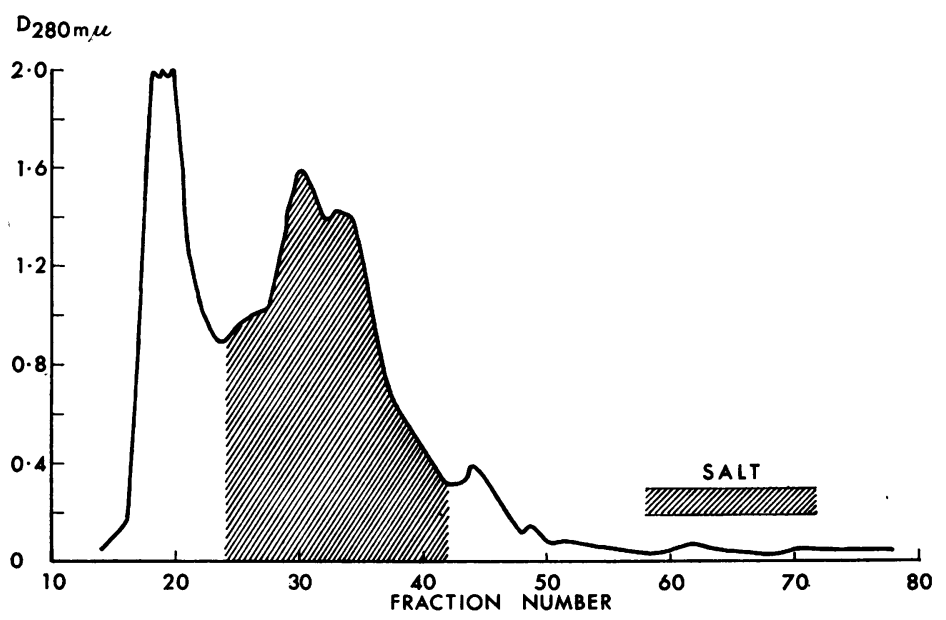

FIG. 2. Fractionation on Sephadex $G 50$ of fraction $A$ from Sephadex G 25 (Fig. 1).

Fraction B was applied in a volume of $1 \mathrm{ml}$ to a column of Sephadex G 10,1 cm $\times 100 \mathrm{~cm}$, packed in $0.04 \mathrm{M}$ ammonium bicarbonate solution. The effluent was collected in fractions of approximately $0.3 \mathrm{ml}$ every 15 minutes and these were read at $280 \mathrm{~m} \mu$. A typical result is shown in Fig. 3; secretagogue activity was found in peaks I, II, and III but not in peak IV. In view of the small amount of total activity present and the incomplete separation of the peaks no attempt was made to deal with them separately; all the active salt-free fractions were pooled, lyophilized, and redried in vacuo over phosphoric oxide until free from ammonium bicarbonate.

FRACTIONATION ON AMINOETHYLCELLULOSE In preliminary trials it was found that the products obtained from the above fractionations on Sephadex G 50 and G 10 both gave the same pattern of peaks when subjected to gradient elution chromatography on aminoethylcellulose despite the obvious difference in molecular size of the material with which the activity was associated in the two cases, as indicated by the separation on Sephadex G 25 (Fig. 1); the explanation seems to be that at this stage some of the activity is electrostatically bound to denatured protein from which it dissociates on the AE column, emerging in the free form. For this reason and in view of the very small amount of active material being dealt with, the products from the $\mathbf{G} \mathbf{5 0}$ and $\mathbf{G} \mathbf{1 0}$ columns were combined for the final stage of isolation on aminoethylcellulose. The salt-free residues were dissolved in $4 \mathrm{ml}$ of $0.02 \mathrm{M}$ ammonium bicarbonate buffer and applied to a column of aminoethylcellulose (Whatman AE 41 $1 \mathrm{~cm} \times 5 \mathrm{~cm}$ ) packed in $0.04 \mathrm{M}$ ammonium bicarbonate buffer. The aminoethylcellulose had been precycled in acid and alkali and freed from 'fines' as recommended by the manufacturers and then washed thoroughly with starting buffer.

After application of the sample, the column was washed with $0.04 \mathrm{M}$ buffer until the absorption at $280 \mathrm{~m} \mu$ of the

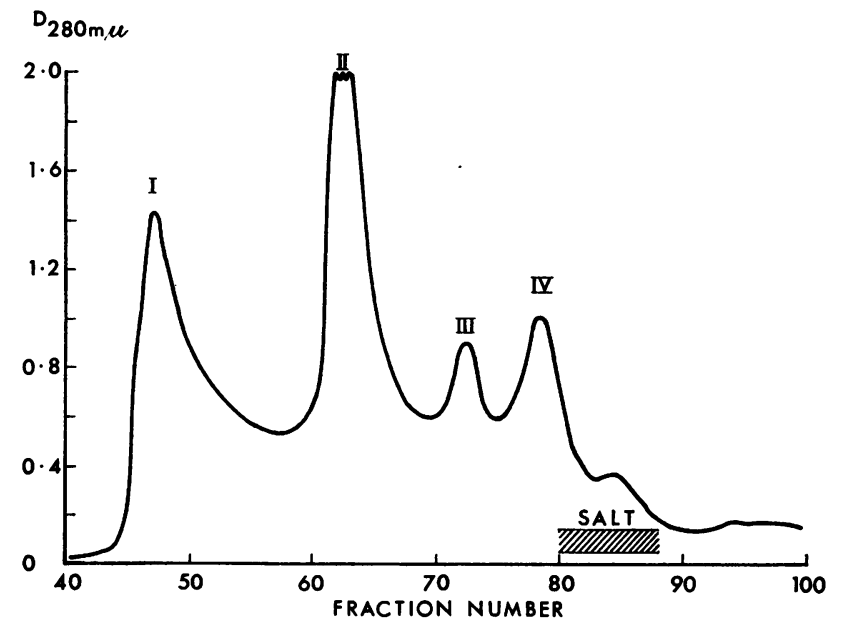

FIG. 3. Fractionation on Sephadex $\mathbf{G} 10$ of fraction $B$ from Sephadex $G 25$ (Fig. 1). 


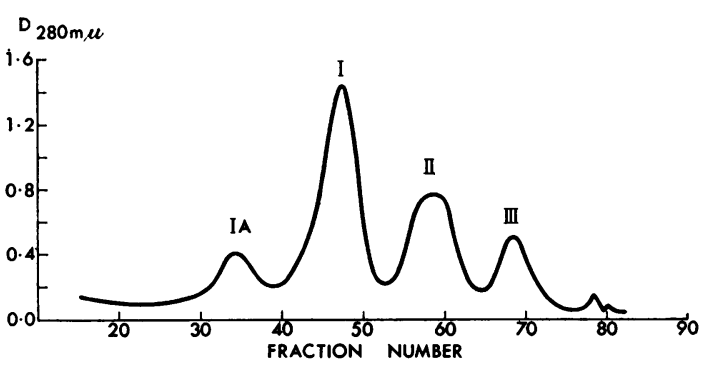

FIG. 4. Fractionation of the combined salt-free active products from Sephadex G 50 (Fig. 2) and G 10 (Fig. 3) by gradient elution chromatography on aminoethylcellulose.

effluent was low and constant; a concentration gradient to $0.4 \mathrm{M}$ buffer was then instituted using a closed magnetically stirred mixing vessel (volume $100 \mathrm{ml}$ ). The effluent was collected in $1.3 \mathrm{ml}$ fractions every 15 minutes and these were read at $280 \mathrm{~m} \mu$. The result is shown in Figure 4.

The fractions corresponding to the four major peaks (designated IA, I, II, and III in order of emergence from the column) were rerun individually on small columns $(1 \mathrm{~cm} \times 5 \mathrm{~cm})$ of aminoethylcellulose using the same gradient as before. Small aliquots of the final products were tested for secretagogue activity and the remainder then used for chemical examination.

QUANTITATIVE AMINOACID ANALYSIS One-fifth of fractions IA, I, and III were hydrolyzed with $1.5 \mathrm{ml}$ of twicedistilled constant-boiling-point $\mathrm{HCl}$ in an evacuated sealed glass tube for 16 hours at $110^{\circ} \mathrm{C}$; the hydrolysate was repeatedly evaporated to dryness under reduced pressure to remove $\mathrm{HCl}$. The residue was dissolved in $1.0 \mathrm{ml}$ of citrate buffer, $p \mathrm{H} 2 \cdot 2$, and applied to a model 120B Beckman-Spinco aminoacid analyser modified for accelerated analysis.

One-fifth of fraction II was hydrolyzed with $1.0 \mathrm{ml}$ of $0.1 \mathrm{~N} \mathrm{NaOH}$ in a closed Teflon tube in absence of $\mathrm{O}_{2}$ for 16 hours at $110^{\circ} \mathrm{C}$. The solution was neutralized, dried, and the residue dissolved in citrate buffer for analysis, as above.

THIN-LAYER CHROMATOGRAPHY This was performed in n-butanol-acetic acid-water $(4: 1: 5 \mathrm{v} / \mathrm{v})$ using silica gel containing starch $(50: 1 \mathrm{w} / \mathrm{w})$ as support. After drying at $100^{\circ} \mathrm{C}$ the plates were developed with a chloroimino reagent (Pan and Dutcher, 1956). This is a sensitive test for proteins, peptides, and most aminoacids (Rydon and Smith, 1952).

HIGH-VOLTAGE PAPER ELECTROPHORESIS Samples were run on Whatman no. 1 paper at 110 volts $/ \mathrm{cm}$ for 30 minutes in a modified Michl-type apparatus using pyridine-aceticacid buffer, $p \mathrm{H} 6 \cdot 5$. The papers were dried and stained with ninhydrin and dimethylaminobenzaldehyde; glutamic acid was used as a mobility marker.

ENZYMATIC DEGRADATION Subtilisin Samples of fraction I and synthetic human gastrin type I, each of $100 \mu \mathrm{g}$, were digested separately with $10 \mu \mathrm{g}$ subtilisin (Teikoku Ltd, Osaka, Japan) in $0.1 \mathrm{ml}$ of a mixture of ammonium bicarbonate $0.1 \mathrm{M}$ and ammonium acetate $0.1 \mathrm{M}$ solutions $1: 5(p \mathrm{H} 8.0)$ at $37^{\circ} \mathrm{C}$ for 36 hours; after 24 hours a further $10 \mu \mathrm{g}$ of subtilisin was added to each reaction mixture. After evaporation to dryness under reduced pressure at room temperature, the residues were dissolved in the minimal volume of water and subjected to paper electrophoresis.

Thermolysin Samples of fraction I and synthetic human gastrin type I, each of $100 \mu \mathrm{g}$, were digested separately with $10 \mu \mathrm{g}$ thermolysin (Daiwa Kasei KK, Osaka, Japan) in $0.1 \mathrm{ml}$ of Tris buffer $0.05 \mathrm{M}, p \mathrm{H} 8.0$, for 12 hours at $40^{\circ} \mathrm{C}$. The enzymatic action was stopped by adding 2 drops of $0.1 \mathrm{~N} \mathrm{HCl}$ and the mixtures were evaporated to dryness. The residues were dissolved in the minimal volume of water and subjected to paper electrophoresis.

\section{RESULTS}

The quantitative aminoacid composition of the four fractions obtained by chromatography on aminoethylcellulose are shown in the Table. These and other data in respect of each fraction may be summarized as follows:

FRACTION IA This could not be shown to stimulate gastric secretion. The aminoacid analysis indicated that it was not homogeneous; its composition bore some resemblance to a gastrin peptide, but valine and serine were present in significant amounts. Thin-layer chromatography showed two major components and a third in trace amount; the former had $R_{f}$ values of 0 and 0.23 , the latter 0.53 ; this is similar to that of human synthetic gastrin $I$ in the same system.

FRACTION I This was highly active in stimulating gastric acid secretion. Its aminoacid composition

\section{TABLE}

AMINOACID CONSTITUTION OF ZOLLINGER-ELLISON TUMOUR FRACTIONS FROM AMINOETHYLCELLULOSE COLUMN

\begin{tabular}{|c|c|c|c|c|c|}
\hline \multirow[b]{2}{*}{ Residue } & \multirow{2}{*}{$\begin{array}{l}\text { Human } \\
\text { Gastrin }\end{array}$} & \multicolumn{4}{|c|}{ Fraction ( } \\
\hline & & $I A$ & $I$ & II & $I I I$ \\
\hline Aspartic & 1 & $0 \cdot 158$ & 1.03 & 1.00 & 1.08 \\
\hline Serine & - & 0.070 & - & - & - \\
\hline Glutamic & 6 & $0 \cdot 580$ & $6 \cdot 10$ & $5 \cdot 60$ & $5 \cdot 82$ \\
\hline Proline & 1 & $0 \cdot 176$ & 1.07 & 1.00 & 0.89 \\
\hline Glycine & 2 & $0 \cdot 188$ & 1.90 & $2 \cdot 20$ & $2 \cdot 30$ \\
\hline Alanine & $\overline{1}$ & 0.139 & 0.97 & $1 \cdot 10$ & 0.96 \\
\hline Valine & - & 0.049 & - & - & - \\
\hline Methionine & 1 & 0.016 & 0.70 & 0.96 & $\overline{0.47}$ \\
\hline Leucine & 1 & $0 \cdot 149$ & 1.03 & 0.70 & 1.00 \\
\hline Tyrosine & 1 & 0.061 & 0.93 & $0.92^{1}$ & 1.04 \\
\hline Phenylalanine & 1 & 0.034 & 0.80 & 0.92 & 0.77 \\
\hline Tryptophan & 2 & & & ent & \\
\hline
\end{tabular}

${ }^{1}$ Present as tyrosine sulphate 


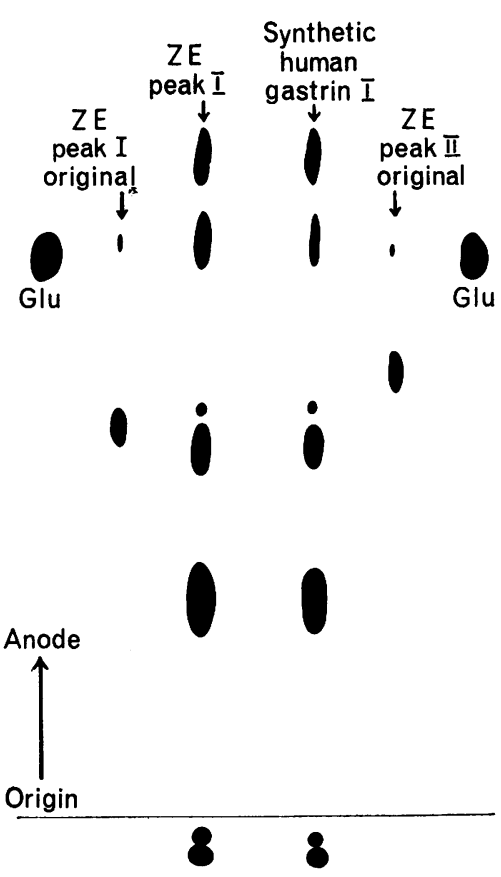

FIG. 5.

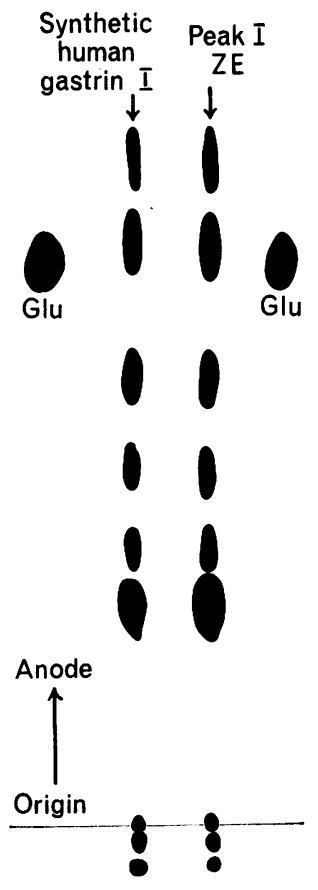

FIG. 6.
FIG. 5. High-voltage electrophoresis of the peptide fragments resulting from digestion by thermolysin of (a) synthetic human gastrin type I and (b) peak I material from fractionation on aminoethylcellulose of Zollinger-Ellison tumour extract (Fig. 4). Samples of unhydrolyzed material from fractions $I$ and II are also included. Glu $=$ glutamic acid markers .

FIG. 6. High-voltage electrophoresis of the peptide fragments resulting from digestion by subtilisin of (a) synthetic human gastrin type I and (b) peak I material from fractionation of ZollingerEllison tumour extract (Fig. 4) on aminoethylcellulose. Glu = glutamic acid markers. was in excellent agreement with that of human gastrin peptide and its position in the elution gradient from the aminoethlycellulose column corresponded to that anticipated for a gastrin type I (unsulphated) on the basis of previous experience. The amount present (calculated from the aminoacid analysis) was approximately $550 \mu \mathrm{g}$. On paper electrophoresis it ran as a single spot with a trace contaminant; the mobility of the former in comparison with that of glutamic acid corresponded with that expected for a gastrin type I (Fig. 5). On thin-layer chromatography it ran as a single spot with a trace contaminant; the mobility of the former corresponded to that of synthetic human gastrin type I. The trace contaminant can be identified as gastrin in which the methionine residues have become oxidized; it is commonly present to this extent in preparations of natural or synthetic gastrin. Direct electrophoretic comparison of the peptide fragments resulting from digestion by the enzymes subtilisin and thermolysin of fraction I and synthetic human gastrin type I (Figs. 5 and 6) showed a perfect correspondence between the two substances, both in regard to the number and mobilities of the fragments.

FRACTION II This was highly active in stimulating gastric acid secretion. Its aminoacid composition showed excellent agreement with that of a human gastrin peptide; the use of alkaline, rather than acid, hydrolysis in preparing the sample for aminoacid analysis established that the single tyrosine residue present was in the sulphated form which is characteristic of human gastrin type II. Its position in the aminoethlycellulose elution diagram corresponded to that expected for gastrin type II. The calculated amount present was approximately $250 \mu \mathrm{g}$. On paper electrophoresis it ran as a single spot with a trace contaminant; the mobility of the former relative to that of glutamic acid corresponded to that expected for gastrin type II. Thin-layer chromatography showed a single spot with a trace contaminant. As mentioned in respect of fraction $I$, the trace contaminant can be identified as oxidized gastrin. Unfortunately no enzymatic degradation studies could be made on fraction II owing to loss of most of the material when the aminoacid analyser broke down on two occasions while analyses of it were in progress.

FRACTION III This was a weak stimulant of gastric acid secretion. Its aminoacid composition was in good agreement with that of a human gastrin peptide apart from rather low values for methionine and phenylalanine. Thin-layer chromatography showed one major component $\left(R_{f}=0.40\right)$ closely followed 
by two minor ones, and a fast-moving trace $\left(R_{\mathfrak{f}}=\right.$ $0 \cdot 71$ ). The amount present, calculated as gastrin, was approximately $200 \mu \mathrm{g}$.

\section{DISCUSSION}

Two peptides (fractions I and II) have been isolated from pooled Zollinger-Ellison tumour tissue which are potent stimulants of gastric acid secretion when injected subcutaneously into conscious pouch dogs. They have the same quantitative aminoacid constitution as the gastrins isolated from human antral mucosa, including the presence of the sulphated form of tyrosine in fraction II as in human gastrin type II. Their electrophoretic and chromatographic behaviour corresponds to that of the human gastrins and they have been found in similar proportions (Gregory, Tracy, and Grossman, 1966).

Electrophoretic comparison of the peptide fragments resulting from enzymatic degradation by subtilisin and thermolysin of fraction I and synthetic human gastrin type I showed a perfect correspondence in their number and mobility. Unpublished studies by one of us (K.L.A.) on the structure of dog gastrin have shown that this method is a powerful one for revealing variations in the position of a single residue, and hence it appears highly probable that the aminoacid sequences of fraction $I$ and human gastrin type $I$ are identical. Proof of this by complete analysis, as carried out for hog gastrin (Gregory, Hardy, Jones, Kenner, and Sheppard, 1964), would require far larger amounts of material than were available here. However, an improved method of peptide sequence analysis using mass spectrometry which has been evolved in this university will, it is hoped, be applicable to future preparations, and this may be expected to provide decisive evidence.

The nature and significance of the components identified in fractions IA and II remains for the present uncertain. If larger preparations can be obtained in the future it may be possible to separate and characterize them more precisely. It seems probable that fraction III consisted largely of gastrin which had become oxidized, perhaps during the process of extraction. This would account for its aminoacid composition, its greater acidity than fraction II (as indicated by its position in the aminoethylcellulose elution diagram) and also its low activity, for Morley, Tracy, and Gregory (1965) found that oxidation of the methionine residue in the C-terminal tetrapeptide amide of gastrin resulted in severe but not complete loss of the power to stimulate gastric acid secretion.

Since the studies reported here were completed, McGuigan and Trudeau (1968) and Stremple and Meade (1968) have described the detection of circulating gastrin in patients with the Zollinger-Ellison syndrome using methods of radioimmunoassay. McGuigan and Trudeau used an antibody raised in rabbits with a conjugate of residues 2-17 of synthetic human gastrin I and bovine serum albumin; Stremple and Mead used an antibody raised in chickens with synthetic human gastrin I adsorbed on polymethylmethacrylate particles. McGuigan and Trudeau found levels of 2,550 to $62,000 \mu \mu \mathrm{g}$ per $\mathrm{ml}$ in four patients, compared with values of 245 to $668 \mu \mu \mathrm{g}$ par $\mathrm{ml}$ in 24 control subjects, and they also assayed the gastrin content of tumour tissue from one patient using the same method. It is not yet known whether one or other, or both, of the gastrins which we have shown to be present in the tumour tissue are released into the circulation.

We would like to express our gratitude to the many friends who made this work possible by providing us with tumour tissue from their patients.

\section{REFERENCES}

Gregory, H., Hardy, P. M., Jones, D. S., Kenner, G. W., and Sheppard R. C. (1964). The antral hormone gastrin. Structure of gastrin. Nature (Lond.), 204, 931-933.

Gregory, R. A. (1958). Gastric secretory responses after portal venous ligation. J. Physiol. (Cond.), 144, 123-137.

(1968). Recent advances in the physiology of gastrin. Proc. roy. Soc. B., 170, 81-88.

-, Grossman, M. I., Tracy, H. J., and Bentley, P. H. (1967). Nature of the gastric secretagogue in Zollinger-Ellsion tumours. Lancet, 2, 543-544.

- , and Tracy, H. J. (1964). The constitution and properties of two gastrins extracted from dog antral mucosa. Gut, 5, 103-114.

$\longrightarrow,-$, and Grossman, M. I. (1966). Human gastrin: isolation, structure and synthesis. Isolation of two gastrins from human antral mucosa. Nature (Lond.), 209, 583.

McGuigan, J. E., and Trudeau, W. L. (1968). Immunochemical measurement of elevated levels of gastrin in the serum of patients with pancreatic tumors of the Zolinger-Ellison variety. New Engl. J. Med., 278, 1308-1313.

Morley, J. S., Tracy, H. J., and Gregory, R. A. (1965). Structurefunction relationships in the active C-terminal tetrapeptide sequence of gastrin. Nature, (Lond.), 207, 1356-1359.

Pan, S. C., and Dutcher, J. D. (1956). Separation of acetylated neomycins $\mathrm{B}$ and $\mathrm{C}$ by paper chromatography. J. Ind. Engng. Chem. Anal. Ed., 28, 836-838.

Rydon, H. N., and Smith, P. W. G. (1952). A new method for the detection of peptides and similar compounds on paper chromatograms. Nature (Lond.), 169, 922-923.

Stremple, J. F., and Meade, R. C. (1968). Production of antibodies to synthetic human gastrin $I$ and radioimmunoassay of gastrin in the serum of patients with the Zollinger-Ellison syndrome. Surgery, 64, 165-174.

Uvnäs, B., and Emås, S. (1961). A method for biologic assay of gastrin. Gastroenterology, 40, 644-648. 